\title{
Neonatal Jaundice and Maternal Oxytocin Infusion
}

\author{
D. P. DAVIES， R. GOMERSALL， R. ROBERTSON， O. P. GRAY， A. C. TURNBULI
}

British Medical fournal, 1973, 3, 476-477

\section{Results}

\section{Summary}

A prospective study of 78 neonates provides evidence for an association between maternal oxytocin infusion and neonatal jaundice. On the second and fifth days infants of mothers whose labour had been induced by amniotomy followed immediately by intravenous oxytocin (group C) had mean total bilirubin levels significantly higher $(P<0.05)$ than did infants whose mothers had had a spontaneous onset of labour and did not require oxytocin (group A). Bilirubin levels in infants of mothers whose onset of labour was spontaneous but required oxytocin to accelerate progress (group B) did not differ significantly from group $A$.

Though these findings suggest a dose dependent effect of oxytocin, other possible explanations are suggested which take into account other drugs administered to the mother and also differences in the corticosteroid status of the groups of infants.

\section{Introduction}

It has recently been suggested that there has been an increase in the incidence of neonatal jaundice, and that this might be due to an increase in the use of oxytocic drugs in the management of labour (Ghosh and Hudson, 1972). Since oxytocin (Syntocinon) is often administered intravenously to induce or accelerate labour in our obstetric unit we have felt it mandatory to make a critical appraisal of this possible relation between the administration of oxytocin to the mother and the level of bilirubin in the neonate. This communication summarizes the results of a prospective study and indicates some possible lines for future research.

\section{Clinical material and methods}

Seventy-eight healthy, full-term infants were studied; haemolytic disease (Rhesus and ABO incompatibility) was excluded. They were divided into the following three groups depending on the pattern of the mother's labour: Group A-Spontaneous onset of labour, no oxytocic drugs (28 infants). Group B-Spontaneous onset of labour, oxytocin given to expedite labour (14 infants). Group C-Labour artificially induced by amniotomy followed immediately by intravenous oxytocin infusion ( 36 infants).

Capillary blood was obtained by heel prick on the second day from each infant and on the fifth day from those infants who were still in hospital. Total serum bilirubin was determined by a spectrophotometric method (White et al., 1958).

\section{Welsh National School of Medicine, Cardiff CF4 4XW}

D. P. DAVIES, M.R.C.P., D.C.H., Lecturer, Department of Child Health R. GOMERSALL, M.R.C.o.G., Research Registrar, Department of Obstetrics and Gynaecology

R. ROBERTSON, M.B., Clinical Assistant, Department of Child Health O. P. GRAY, F.R.C.P., D.C.H., Professor, Department of Child Health A. C. TURNBULL, M.D., F.R.c.o.G., Professor, Department of Obstetrics and Gynaecology
Individual and mean values ( \pm S.D.) for each group on the second and fifth day are presented diagrammatically in the figure, and analysed statistically in table I. On both the study days the infants of mothers whose labour had been artificially induced with oxytocin (group C) had a mean total bilirubin level which was significantly higher $(P<0.05)$ than that in the infants whose mothers had gone spontaneously into labour and who did not require any oxytocin during labour (group A). On the other hand infants of mothers whose labour was of spontaneous onset but required oxytocin to accelerate progress (group B) did not have a significantly raised mean bilirubin level when compared with group $A$ infants.

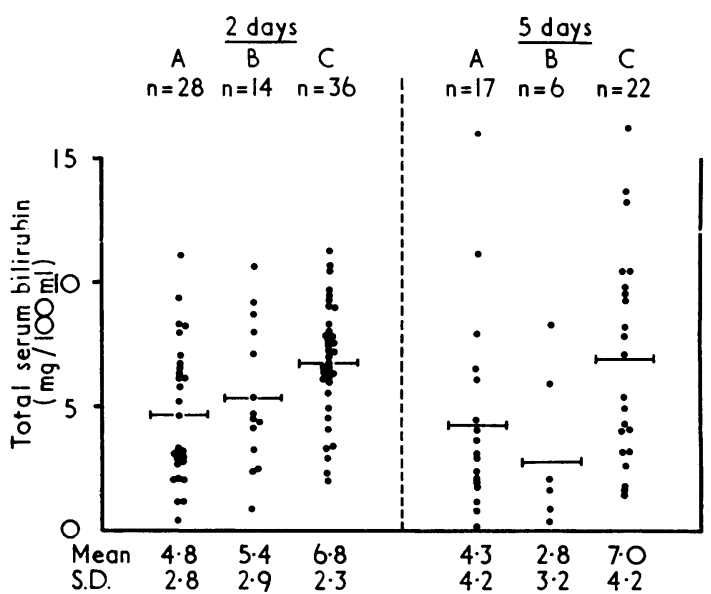

Total serum bilirubin levels on second and fifth days in the three infant groups. Group A-Spontaneous onset of labour. No oxytocin. Group BSpontaneous onset of labour. Oxytocin (Syntocinon) given to expedite labour. Group C-Labour artificially induced by amniotomy followed immediately by intravenous oxytocin infusion.

TABLE I-Mean Total Bilirubin Levels in $\mathrm{mg} / 100 \mathrm{ml}( \pm$ S.D.) in the Three Infant Groups

\begin{tabular}{|c|c|c|c|c|}
\hline & & Group A & Group B & Group C \\
\hline 2nd day .. & . & $4 \cdot 8(2 \cdot 8)(n=28)$ & $5.4(2.9)^{*}(n=14)$ & $6.8(2.3)+(n=36)$ \\
\hline 5th day .. & . & $4 \cdot 3(4 \cdot 2)(n=17)$ & $2 \cdot 8(3 \cdot 2) *(n=6)$ & $7 \cdot 0(4 \cdot 2)+(n=22)$ \\
\hline
\end{tabular}

*When compared with group A: not significant $(P>0.05)$.

When compared with group A: not signific
tWhen compared with group A: $P<0.05$.

The distribution in groups A, B, and C of birth weight, gestational age, breast-feeding, and operative delivery, all of which are known to influence the level of bilirubin in the neonate are shown in table II. Since the factors are similarly represented in all three groups they are unlikely to account for the higher total bilirubin levels found in infants of group C.

Investigations into possible causes of neonatal jaundice require details of drugs used not only during labour but also towards the end of the pregnancy. The main drugs which were given to the mothers in our study during labour and in the 24 hours before the onset of labour are summarized in table III. From this it appears that in mothers whose labour had been artificially induced with oxytocin (group C), nitrazepam (Moga- 
rABLE II-Distribution wi thin the Three Groups of Certain Fetal and Materna Factors which can have a Role in Production of Neonatal Hyperbilirubinaemia

\begin{tabular}{|c|c|c|c|}
\hline Factors & Group A & Group B & Group C \\
\hline 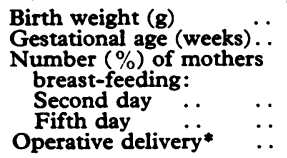 & $\begin{array}{c}3,375 \\
39 \cdot 3 \\
\\
10(36 \%) \\
6(21 \%) \\
14(50 \%)\end{array}$ & $\begin{array}{l}3,355 \\
39 \cdot 1 \\
\\
7(50 \%) \\
3(21 \%) \\
6(43 \%)\end{array}$ & $\begin{array}{c}3,300 \\
39 \cdot 2 \\
\\
13(36 \%) \\
8(22 \%) \\
17(47 \%)\end{array}$ \\
\hline
\end{tabular}

*Forceps or ventouse assisted delivery in all instances except for three caesariean sections; one in group $A$ and two in group $C$.

TABLE III-Drugs Used During Labour and in 24-hour Period before Onset of Labour

\begin{tabular}{|c|c|c|c|c|}
\hline Drugs & & $\underset{(n=28)}{\text { Group } A}$ & $\begin{array}{c}\text { Group B } \\
(n=14)\end{array}$ & $\begin{array}{l}\text { Group } \\
(n=36)\end{array}$ \\
\hline $\begin{array}{l}\text { Before labour: } \\
\text { Nitrazepam (Mogadon)* } \\
\text { During labour: } \\
\text { Pethidine } \\
\text { Perphenazine (Fentazin) } \\
\text { Bupivacaine (Marcaine) } \\
\text { Diazepam (Valium) ... } \\
\text { Nitrous oxide and oxygen } \\
\text { Methoxyflurane (Penthrane) }\end{array}$ & $\begin{array}{ll}\cdots & \cdots \\
\cdots & \cdots \\
\cdots & \cdots \\
\cdots & \cdots \\
\cdots & \cdots\end{array}$ & $\begin{array}{r}3(11 \%) \\
12(43 \%) \\
13(46 \%) \\
4(14 \%) \\
3(11 \%) \\
2(7 \%) \\
16(57 \%)\end{array}$ & $\begin{array}{r}1(7 \%) \\
8(57 \%) \\
11(79 \%) \\
2(14 \%) \\
2(14 \%) \\
5(36 \%) \\
7(50 \%)\end{array}$ & $\begin{array}{r}23(64 \%) \\
23(64 \%) \\
15(42 \%) \\
24(66 \%) \\
5(14 \%) \\
2(5 \%) \\
15(42 \%)\end{array}$ \\
\hline
\end{tabular}

*Prescribed as a night hypnotic before the onset of labour.

don) and bupivacaine (Marcaine-used for epidural analgesia) are more highly represented when compared with the other two groups, whereas the remaining drugs are fairly evenly distributed among the three groups.

\section{Discussion}

Though the numbers of infants in the present study are small the findings imply that oxytocin administration may have been responsible for the higher bilirubin values found in infants born to women whose labour had been induced with oxytocin. It is interesting that the infants of mothers given oxytocin to expedite delivery after spontaneous onset of labour (group B) had a mean bilirubin level not differing significantly from that in infants of mothers not given oxytocin (group A). It seems possible that the effect of oxytocin may be dose dependent, for in group B the average maximum infusion rate was only $12.0 \mathrm{mU} / \mathrm{min}$ (range $2-32$ ) while in group $C$ it was $16.8 \mathrm{mU} / \mathrm{min}$ (range $1.5-32$ ). Furthermore, the average duration of oxytocin infusion was less in group B ( $5 \mathrm{hr} 45 \mathrm{~min})$ compared with group C (7 hr $20 \mathrm{~min})$.

On the other hand this association between higher neonatal bilirubin levels with maternally administered oxytocin might be spurious. Perhaps the infants in group $\mathrm{C}$ are peculiarly susceptible to developing a greater degree of neonatal hyperbilirubinaemia. Pursuing this line of argument it may be that other drugs given to the mothers are involved and what is being observed is a cumulative drug effect. Nitrazepam and bupivacaine were used much more in the mothers of group $C$ (table III) and they may be responsible, though there are no preceding references in the literature to an association between these drugs and neonatal hyperbilirubinaemia. Detailed investigations of liver and red cell function will be required before the association between maternal oxytocin administration and neonatal hyperbilirubinaemia can be explained.

A third possibility takes into account the differences in corticosteroid status of the infant groups. Murphy (1973) has shown that at birth the umbilical cord serum cortisol levels are higher when labour has been of spontaneous onset than when induced, and these findings have recently been confirmed in Cardiff (Anderson et al., 1973). Furthermore, this naturally occurring cortisol spurt towards the end of pregnancy might have an important role in the maturation of organ systems which are necessary for extrauterine survival (Murphy, 1973). An increasing number of liver enzymes are now known to be corticosteroid inducible (Rose and Braidman, 1970; Curzon, 1969), and it might be expected that the hepatic enzymes necessary for the excretion of bilirubin are also of this category. Adrenocorticosteroids could then be seen to have an important function in preparing the fetal and neonatal liver to manage the early postnatal bilirubin load. If this were so, the association between maternal oxytocin infusion and neonatal hyperbilirubinaemia would then be spurious, instead reflecting a level of relative hepatic enzyme immaturity in the offspring of women who do not spontaneously enter parturition.

It is important to view this association in perspective, however, particularly since oxytocin infusion is now such a common and invaluable agent in the management of labour in avoiding prolonged and difficult labour and operative delivery. An analogy with breast milk jaundice would seem reasonable. Breastfeeding is a well recognized causal factor in the production of neonatal jaundice (Arias et al., 1964) and a bilirubin level above $10 \mathrm{mg} / 100 \mathrm{ml}$ is not infrequent in full term, breast-fed infants during the first week of life. It is unlikely that harm results from this degree of hyperbilirubinaemia and in clinical practice it is rarely a sufficient indication for discontinuing breast-feeding. In the present study there was nothing to suggest that any neurological damage would result from the infants' higher bilirubin levels in group $C$ and during the whole study only two required treatment wih phototherapy, one each in group $A$ and group C. Nevertheless, bilirubin neurotoxicity can no longer be regarded an "all or none" phenomenon. In fact, a wide spectrum of brain damage is recognized which can range from a mild disturbance in cognitive function to death from kernicteris (Lucey, 1972). The minimum bilirubin level at which such brain damage can develop in the full term infant remains unknown, and though it has been suggested that in the absence of hypoxia, hypothermia, acidosis, or a low serum albumin a bilirubin level of $20 \mathrm{mg} / 100 \mathrm{ml}$ or less has no effect on subsequent I.Q. (British Medical fournal, 1972), this is clearly not an area for complacency. Further work is required not only on the relation between maternal oxytocin infusion and neonatal jaundice but also on the finer details of bilirubin neurotoxicity in the long term.

We thank Miss S. Muxworthy, Mrs. J. Garlick, and the blood bank for technical help; the nursing staff of the Obstetrics Department, University Hospital of Wales, for their willing oo-operation; and Miss Ann Griffin and Mrs. M. D. Johnson for secretarial help.

Requests for reprints should be addressed to: Dr. D. P. Davies, Department of Child Health, Welsh National School of Medicine, Health Park, Cardiff CF4 4XW.

\section{References}

Anderson, A., Cawson, M., and Turnbull, A. C. (1973). In press.

Arias, I. M., Gartner, L. M., Seifter, S., and Furman, M. (1964). Fournal of Clinical Investigation, 43, 2037.

British Medical fournal $1972,2,62$

British Medical fournal, 1972, 2, 62.

Curzon, G. (1969). British Fournal of Psychiatry, 115,
Ghosh, A., and Hudson, F. P. (1972). Lancet, 2, 823.

Ghosh, A., and Hudson, F. P. (1972). Lancet, 2, 823.

Murphy, B. E. P. (1973). American fournal of Obstetrics and Gynaecology, 115,521 .

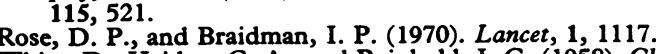

White, D., Haidau, G. A., and Reinhold, J. G. (1958). Clinical Chemistry, 4, 211. 